\title{
The Sense of Hearing in Fish*
}

\author{
By Prof. K. von Frisch, University of Munich
}

$\mathrm{T}^{\mathrm{T}}$ HERE is an old dispute as to whether fish are able to hear or not. It has seemed improbable that they can. Three main reasons have been brought forward against it.

(1) A biological reason : most fish seem to be dumb; a sense of hearing would therefore not be of biological significance for them.

(2) An anatomical reason : the inner ear of mammals has two main functions. It is the organ of equilibrium and the organ of hearing. Perception of equilibrium is the function of the utriculus and the semicircular canals. It is not yet clear if the sacculus of mammals has to do with equilibrium or with hearing. At the sacculus we find the cochlea; it is generally supposed that the cochlea alone is the organ of hearing. Comparative anatomy shows that there is no cochlea in the inner ear of fish. We find only a
S. C.

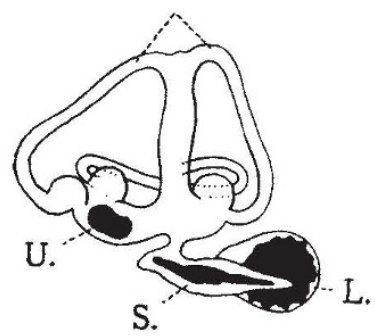

Fig. 1.

The TABYRINTH OF A MINNOW. $U=$ UTRICULUS; S.C. = SEMICIRCULAR CANALS ; $S=$ SACCULUS ; $L=$ LAGENA. periments, but they experiments, but they could not observe any reaction of fish to sound. But on this point there is no agreement. For example, American investigators, especially Prof. Parker and his collaborators, made experiments with various fish with positive results. Opponents, especially in Germany, could not confirm it. It was argued that if there is a reaction to sound it would be a reaction to the movement of water and not to sound vibration--it would not be true hearing.

So the question arises: What is hearing? I think that, in vertebrates, it is not difficult to define it. Human beings can perceive very loud sounds by means of the skin and by means of the inner ear. Perception through the skin we call

* Substance of a lecture delivered at University College, London, on March 4, 1937. feeling ; perception through the inner ear we call hearing. In all vertebrates the inner ear is a homologous organ. We should only speak about 'hearing' in the case of the perception of sound vibrations by means of the inner ear in vertebrates.

But the first question must be: Is there a reaction to sounds in fish? There was no agreement on this point. Many observers could not see any reactions to whistling, or to notes from a violin, or to the voice of a singer, and so on. But that is not astonishing. The voice of a singer or the sound of a violin or whistle is not of the slightest biological significance for fish. We should not wonder, therefore, if they do not react to it.

I thought, however, it might be possible to give a biological significance to sounds. If we whistle every time when we give food to the fish, then whistling acquires a biological significance, because the food is announced by it. First I performed the experiment in the following manner. I had a little catfish, Amiurus nebulosus, in an aquarium. It lay mostly in an earthenware pipe put on the bottom of the aquarium. The fish was blind, both eyes having been removed, and so it could not see what happened. It got the food from a glass feeding-rod. When the food was brought near the opening of the pipe the fish perceived the meat by means of its chemical sense, came out and swallowed the food. Then, every time I gave it food, I whistled with my lips. Thus I tried to train the fish to the whistling. After some days the fish came out when I whistled before I put the feeding-rod into the water, swam upwards and sought for the food; and always after that it could be called out by soft whistling not only from nearby but also from a considerable distance, for example, from the other side of a large room.

Later these experiments were continued by my collaborator, Dr. Stetter. He used various kinds of fish. The best results were given by our little minnows (Phoxinus loevis), and therefore they have been studied very thoroughly. To produce sounds tuning forks were generally used for low sounds and whistles for the higher ones. The sense of sight was eliminated by removal of the eyes. Then the fish was trained to a certain sound by four to five training feedings daily. After a few days the fish gives a very typical reaction to sound. The kind of reaction varies from individual to individual. When the sound is given, some fish dive down and snap for food on the bottom, others go up and snap on the surface, others stop and 
snap vigorously on whatever spot they may be, but all snap and seek for food because they are accustomed to get the food when the sound is given. After a few seconds we put the feeding. rod into the water; the fish gets the food, and so the training is continued.

There is not the slightest doubt that there are clear reactions to sound. Further experiments by Dr. Stetter gave a great many results. It seems to me that three of them are of special interest.

Dr. Stetter tried to train fish to very low and to very high sounds, and so to find out the limits of the sense of hearing. The upper limit in minnows is between $D^{5}$ and $A^{5}$ (about 5,000-7,000 vibrations a second). Training to higher sounds is without results. There are slight individual differences; but there is a far greater difference between various species of fishes. Thus Amiurus gave positive results up to 13,000 vibrations a second. This is about the same upper limit as in human beings. Dr. Stetter was unable to find a lower limit. The lowest tuning fork, $C_{2}$ (frequency $16)$, gave good results.

A second result concerns the acuteness of the sense of hearing. A minnow was trained to $E^{2}$ (frequency 660). Then the sound of the whistle was diminished gradually to a very low intensity. The aquarium was put on a table in a long corridor and the soft whistle was given from farther and farther away in a series of experiments until reactions could no longer be obtained. Reactions could be obtained from a distance of about 200 feet. We ourselves could hear the whistle from that distance only as a very weak sound. But it is difficult to understand what this means, because we do not know to what extent the sound is weakened on entering the water. We therefore brought a large aquarium to the same spot and one of our students dived down and was tested in just the same manner as the fish. The experiment showed that our best fishes could hear as well as men in the aquarium, or even a little better than men. It was very surprising to us.

The third result concerns the discrimination of sounds. It is possible to prove that minnows can distinguish between different sounds. The following method was employed. A fish is trained to a certain sound, that is, the feeding sound. When there is a good feeding reaction, we introduce another sound one or two octaves higher or lower than the feeding sound. But at this sound no food is given, and if the fish begins to snap and seek for food, it is punished by a light blow with a glass rod. This other sound we call the warning sound, because it means a punishment. After some time of training, the fish gives the feeding reaction only to the feeding sound; to the warning sound it gives no reaction, or even a very distinct flight reaction to avoid the punishing blow. Now the interval between the two sounds can be gradually decreased, and thus we can find out what interval can be distinguished. Most fishes can easily be trained to distinguish between two sounds at an interval of one octave. The best fish could distinguish perfectly between the two sounds of a minor third, $D^{1} / F^{1}$ (frequencies 290 and 345 ).

During 1936, Dr. Wohlfahrt in our laboratory was able to improve these results by employing a new method. In the experiments of Dr. Stetter there was always a period of at least a quarter of an hour between the feeding sound and the warning sound. The fish, therefore, had to keep the sound in mind and decide by memory. It was clear from these experiments that the fish has some sense of absolute hearing - but not a very good one. Wohlfahrt gave short sounds so that they immediately followed one another, just like a trill. In this way he was able to show that minnows are able to distinguish even a half-tone interval.

Judging from all these results, it is very probable that there is a true sense of hearing in fishes. To be certain we must seek for the organ of perception.

Experiments have been published by Prof. Parker and his collaborators indicating that the inner ear especially has to do with hearing in fishes. Some observations seemed to show that the sacculus especially, or the lagena, would be the seat of the sense of hearing. But the results were not very convincing, because the methods employed to eliminate the sacculus and the lagena were not satisfactory. The method of training the fishes to sound, combined with careful operations, promised a clear result.

I removed various parts of the labyrinth in minnows. I tried first to remove the utriculus and the ampullæ and to leave the sacculus and the lagena intact. There is no difficulty in doing this. To perform the operation the fish is narcotized by means of a 0.5 per cent solution of urethane. As soon as the fish recovers from the narcotic we find that it has completely lost its sense of equilibrium. It lies on one side on the bottom of the aquarium, and when it swims it turns over and curves the body in a peculiar manner. Nevertheless, it is possible to train such fish to sounds as easily as normal ones. Training can be carried out in the same manner, in the same time, and within the same limits as in the case of normal fishes. There is not the slightest sign that the utriculus and the ampullæ have anything to do with the sense of hearing. They are only organs of equilibrium. It is more difficult to remove the sacculus and the lagena ; but I have succeeded in doing this. It was very surprising to see that such fish, with both sacculi and lagenæ and their large otoliths removed, swim in perfect equilibrium. But it is 
impossible to train them to sounds. Generally I did with each of them more than a hundred training feedings, but the fish gave no reactions to the sounds. Normal fish or fish only operated upon on one side gave reactions after five to fifteen training feedings. I carried out the experiment also in the following manner. I trained a normal fish to a sound. Then it was operated on on one side. The reaction was as clear as before. The fish was operated on on the other side, and then it was never possible to get any reactions.

All this applies only to sounds higher than $C$ (frequency 130). The fish without sacculus and lagena can be trained to low sounds, if they are loud enough. It can even distinguish between different sounds in the low region as well as normal

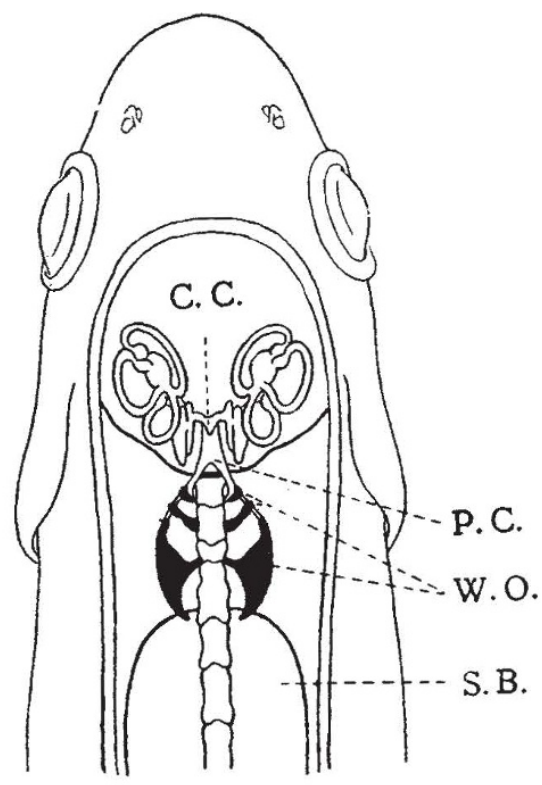

Fig. 2.

C.C. = CROSS CANAL, CONNECTING THE SACCULI WITH ONE ANOTHER; P.C. = POSTERIOR CAVITY; W.O.=

WEBERIAN OSSICLES; S.B. = SWIM BLADDER.

fish. The low sounds are perceived as well as before, even if the whole labyrinth is taken away or if the sense organs of the lateral line, too, are fully destroyed. We can therefore assume that the low sounds are perceived through the skin.

From special experiments it can be concluded that the lowest sounds are perceived only with the skin, low sounds from frequency 25 up to about 130 with the skin and with the inner ear, and all the middle high and very high sounds from about frequency 130 up to the upper limit only with the labyrinth. That is more or less the same as in human beings.

It is stated above that minnows, in the region of middle high sounds, can distinguish between different sounds even when there is an interval of only half a tone. Now we know that these sounds are perceived by the sacculus and lagena. Thus we find that there is a remarkable ability to distinguish between different sounds in the fish labyrinth, in spite of the lack of a cochlea and therefore in the absence of a membrana basilaris. The function of the cochlea and of the membrana basilaris in higher vertebrates may be to improve the discrimination of sounds to the high degree known in man.

Certain anatomical facts are very important for understanding the acuteness of the sense of hearing in minnows. In minnows, as in all Cyprinids, there is a connexion between the labyrinth and the swim bladder by means of the Weberian ossicles. The sacculus of the right and left labyrinths are connected with one another by a cross canal (Fig. 2, C.C.) with a posterior cavity behind the labyrinth (P.C.) with one opening on each side. The opening is closed by a little bone connected with other bones by articulation (W.O.), the last of which is fixed to the anterior end of the swim bladder (S.B.). Sound vibrations in water must be transmitted to the swim bladder, from the swim bladder by means of the little bones to the cavity, from there to the cross canal and thence to the sacculus. Now it is very interesting that the shape of the otolith of the sacculus seems to make it suitable to take up the vibrations coming from the cross canal-a fact first recognized by the Dutch worker, Prof. de Burlet, in Amiurus.

We want to know, however, whether this connexion is necessary for sound perception. Consequently I took away the swim bladder through an incision in the ventral body wall of the minnow. I closed the wound by a suture and after recovering the minnows could be trained to sounds as before. But the acuteness of the sense of hearing was very much reduced. It seemed from these experiments that this connexion between the swim bladder and the sacculus might increase the acuteness of hearing.

If that were true, we should find a sense of hearing very well developed in all fishes possessing Weberian ossicles. All five species of Cyprinids which have been trained for sounds in our laboratory up to now have a very well-developed sense of hearing. The same is true for Amiurus, which belongs to the Silurids. They have Weberian ossicles too. On the other hand, in families having no connexion between the swim bladder and the inner ear, the sense of hearing is very poorly developed. We tried to train for sounds pike, perch, trout, eels and others. Some of them gave no results at all, others could be trained, but the sounds had to be made much louder than for Amiurus or for minnows, and the high sounds were never perceived. 
Besides Cyprinids and Silurids there are two other families possessing Weberian ossicles : Characinidæ and Gymnotidæ. We trained a Gymnotus and some Characinidæ and found a well-developed sense of hearing in all these fish.

Now I wish to direct attention to a peculiar anatomical fact often mentioned in books of comparative anatomy, but never understood. In the Mormyrids, a family of African fish, there is a gas bladder on each side of the skull connected directly with the sacculus. In early embryological stages it is developed as a double cavity of the swim bladder, growing into the head. Later the connexion with the swim bladder is lost by degeneration and the two small air bladders lie completely separated in the skull. I thought that the function of these little air bladders might be the same as that of the big air bladder in minnows and other fishes possessing Weberian ossicles. Sound vibrations reaching the air bladders should cause vibration of them. In this case the stimulus can be transmitted directly to the sacculus, and therefore Weberian ossicles are not necessary. If that is true, we should expect a very well-developed sense of hearing in Mormyrids, although they do not have Weberian ossicles. It was rather difficult to get living Mormyridæ, and we looked for them for several years without success. But finally we got them. We began to train them for sounds with much interest, and we found with satisfaction that they could hear just as well as our best minnows. The anatomical peculiarities of these interesting labyrinths are now being studied in our laboratory.

It may well be asked for what purpose fishes are able to hear so well in silent water. It is not true that all fish are dumb. We know many species of sound-producing fish. There may be many more species of sound-producing fishes not yet known. Some years ago, Dr. Dykgraaf in our laboratory found out that minnows, too, are sound-producing fishes. If they are excited, a soft piping comes from the aquarium. The noise is very soft, but knowing the acuteness of the sense of hearing, we may be sure that it can be heard by the minnows. It is interesting that the production of sound by so well known a fish should have been overlooked for so long. There may be much to discover in the future about the language of fishes.

\section{Organ Pipes and Edge Tones}

\section{By Dr. G. Burniston Brown, University College, London}

$\mathrm{O}^{\mathrm{R}}$ RGAN pipes have long been a favourite theme for the musician and for the physicist, but they are very far from being the simple structures idealized in the text-books. One source of complication in the actual organ pipe is the behaviour of the air stream at the mouth, which results, for example, in the note produced by blowing in the normal manner being higher in pitch than the natural note of the pipe considered as a resonator.

Another problem connected with the phenomena at the lip is the variation of pitch with the pressure of the air supply: in fact, one of the most puzzling features of the behaviour of organ pipes is the curious succession of tones which is evoked when they are underblown, that is to say, when the air is admitted with slowly increasing pressure. The subject has been investigated by Rayleigh ${ }^{1}$, Lutz $^{2}$, Gunnaiya and Subrahmaniam ${ }^{3}$ and others, and although it had been suggested that the pipe tones were initiated by edge tones, no observations of their relationship were made. A recent investigation has helped to make the production of these tones clearer by showing that they are intimately connected with the general problem of edge tones.

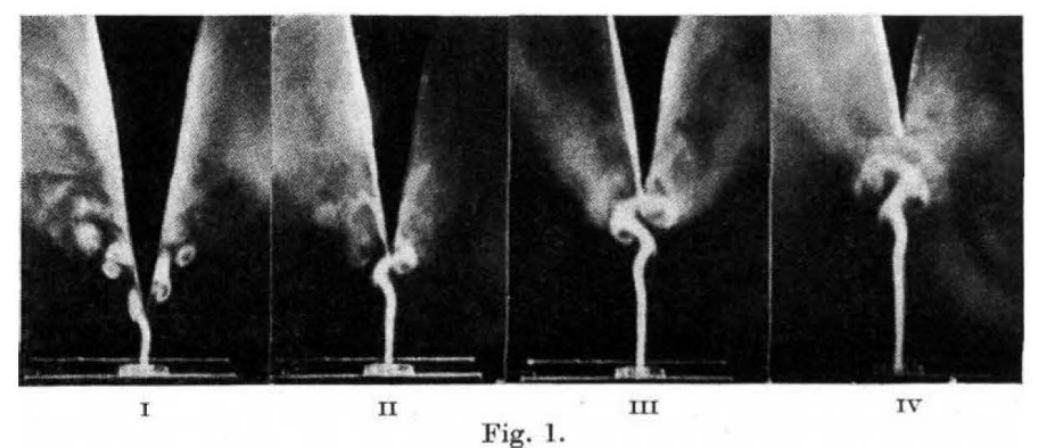

Stages of vortex formation When aIR Impinges on a WedGe. 